\title{
DO TERRITÓRIO DA SECA À TERRITORIALIZAÇÃO DO CANAL DO SERTÃO EM ALAGOAS
}

\author{
FROM THE DROUGHT TERRITORY TO THE TERRITORIALIZATION OF THE CANAL OF SERTÃO IN ALAGOAS
}

\section{RESUMO}

O Canal do Sertão se apresenta como a maior e mais moderna obra hídrica do estado de Alagoas, configurando-se como importante artefato introduzido no polígono das secas do estado com a finalidade de aplacar os problemas sociais decorrentes dos baixos índices pluviométricos que frequentemente acometem o semiárido alagoano. Dentro deste contexto, realizamos uma análise das territorialidades do uso da água ao longo do referido canal, especificamente nos municípios de Delmiro Gouveia e Água Branca, na busca de entender como se formam as territorialidades ao longo do mesmo, a partir do uso da água. Nesse sentido, foi realizada uma coleta de dados oficiais em secretarias do estado, envolvidas diretamente no processo de implantação do canal e em órgãos federais e municipais, finalizando com uma aplicação de entrevistas não-diretivas aos sujeitos envolvidos no uso da água do Canal do Sertão na área foco da pesquisa, podendo assim inferir sobre os usos da água e a dinâmica das territorialidades ao longo do canal. A fundamentação teórica parte dos conceitos de território, territorialização e territorialidade, considerando o território como uma construção geopolítica permeado pelas relações de poder, e suas múltiplas territorialidades.

Palavras-chave: Canal do Sertão, Semiárido, Território, Territorialidades.

\section{ABSTRACT}

The Canal of Sertão shows itself as the biggest and most modern waterworks in the state of Alagoas, constituting itself as an important artifact introduced in the drought polygon of the state in order to appease the social problems caused by the low pluviometric indexes that frequently affect the semi-arid alagoano. Within this context, we carried out an analysis of the territorialities of the use of water along the channel, specifically in the municipalities of Delmiro Gouveia and Água Branca, in the search to understand how territorialities are formed along the canal, from the use of water. In this sense, in order to reach the proposed objective, a collection of official data was carried out in state secretariats, directly involved in the process of channel implantation and in federal and municipal agencies, ending with the application of non-directive interviews to the subjects Involved in the use of the Canal of Sertão water in the research focus area, thus being able to infer about the uses of water and the dynamics of the territorialities along the channel. We have as presuppositions for the theoretical foundation the concepts of territory, territorialization and territoriality, considering the territory as a geopolitical construction permeated by the relations of power, and its multiple territorialities.

Keywords: Canal of Sertão. Semi-arid. Territory. Terrioriality.
Wanubya Maria Menezes da Silva ${ }^{\text {a }}$

Paulo Rogério de Freitas Silva ${ }^{b}$

a Universidade Federal de Sergipe (UFS), Aracaju, SE, Brasil

${ }^{\text {b }}$ Universidade Federal de Alagoas (UFAL), Maceió, AL, Brasil

DOI: $10.12957 /$ geouerj.2020.28890

Correpondência: wanubya.silva@gmail.com

Recebido em: 24 mai. 2017

Revisado em: 11 ago. 2018

Aceito em: 4 fev. 2020 


\section{INTRODUÇÃO}

Na América do Sul três grandes áreas têm como clima predominante o semiárido: a região Guajira na Venezuela e na Colômbia, a diagonal do Cone Sul que conglomera a Argentina, Chile e Equador e o Nordeste do Brasil. As características desse tipo de clima são de temperaturas anuais muito elevadas (média de 25ํㅡ no semiárido brasileiro) com índices pluviométricos muito baixos e irregulares ao longo do ano (100 a $300 \mathrm{~mm}$ ) com prolongados períodos de carência hídrica, provocando a formação de solos arenosos e quase sempre deficientes em elementos nutritivos e, a ausência de rios perenes. O Nordeste Seco brasileiro comporta-se como uma região subdesértica paradoxal, já que é servido por redes hidrográficas hierarquizadas, que nascem nas chapadas e acabam por engrossar as águas do Rio São Francisco e do Rio Parnaíba, os dois rios perenes que cortam a região (AB'SABER, 1999). Acrescentamos que essa grande área, que tem como clima predominante o semiárido, foi classificado por Ab’Saber (1999) como Sertões Secos.

Os Sertões Secos abrangem, dentro da grande macrorregião geográfica nordestina do IBGE, uma área total de $980.056,7 \mathrm{~km}^{2}$, segundo a nova delimitação do semiárido brasileiro, apresentada pelo Ministério da Integração Nacional em 2005.

Nesse recorte socioespacial habitam, segundo o Censo Agropecuário de 2006, 20.870.020 habitantes. Destes, 9.108.972 são residentes do campo, que representa 48,8 \% da sua área dividida em estabelecimentos agropecuários, abrangendo os estados de Alagoas, Bahia, Ceará, Paraíba, Pernambuco, Piauí, Rio Grande do Norte, Sergipe e norte de Minas Gerais

No semiárido brasileiro, historicamente, o clima tomou o papel central nos debates políticos e ideológicos quando o assunto era o drama social da população ali residente, como se este emanasse genuinamente dos efeitos da seca. Fazendo uma rápida revisão literária, não é difícil perceber que a seca como característica do clima semiárido protagonizou os discursos agregados às problemáticas sociais vividas pela população residente no Nordeste seco.

Com uma carência de precipitações que dura de seis a sete meses, e com uma precipitação média anual de 268 a 800 mm (número 2,5 vezes menor que o nível de precipitação da Zona da Mata Nordestina), o clima do Nordeste Seco foi trabalhado como um fator determinista para os flagelados da terra semiárida, o que veio a justificar a territorialização de uma dinâmica indústria da seca, que autorizou a introdução de várias políticas públicas apresentadas como uma via para o desenvolvimento do Nordeste brasileiro.

Este imaginário determinista foi responsável pela produção de uma dinâmica indústria da seca, que serviu de palanque a muitos políticos da oligarquia local, como também aos incentivos migratórios que ajudou a compor um verdadeiro exército de reserva nas grandes metrópoles do Centro-Sul. Com esse imaginário, 
historicamente, a intervenção para o desenvolvimento dessa região foi pontual e com objetivos e interesses bem definidos, vide as políticas emergenciais de frentes de trabalho e a construção de barragens, que quase sempre ficavam dentro das terras da elite agrária local, o que criava uma verdadeira situação de dependência entre a população e o latifundiário.

Somente a partir de 2002, com a eleição do presidente Luiz Inácio Lula da Silva um conjunto de ações começam a ser executados em torno do desenvolvimento rural, que havia iniciado o seu debate no governo anterior. Nesse sentido, há uma ampliação dos programas de transferências de renda e uma galeria de projetos hídricos para o Nordeste brasileiro entram na agenda para o desenvolvimento do semiárido nordestino. Dentro desse contexto emerge o ideário das políticas públicas para o Desenvolvimento Rural, como forma de tornar mínima a migração para as metrópoles e garantir a produção alimentar que atenda às necessidades da população brasileira.

Dentro desta lógica, o Estado brasileiro sustentou o financiamento para a introdução de objetos técnicos ao território na articulação para a construção de bases artificiais na acumulação de água, represamento e transposição, contando com a modernização técnica do território nacional originando uma reorganização do espaço.

\section{Os Sertões Secos e as Políticas de Combate a Seca}

No recorte espacial dos Sertões secos, o clima assumiu o papel central na formulação dos discursos políticos e também serviu como importante recurso ideológico. Este cenário levou a geógrafa Castro (1996, p. 2), a destacar que:

\footnotetext{
As especificidades do ecossistema semiárido possibilitaram um modo de ocupação e um sistema de atores que fizeram em conjunto um espaço muito particular. Esse espaço tem sido apresentado historicamente pelo filtro da conscientização coletiva sobre as dificuldades impostas por este meio que depende dos azares climáticos. A natureza aí é um ente quase metafísico, é fortemente fantasiada e trabalhada nos discursos, da e sobre a região, como um obstáculo intransponível a qualquer progresso ou justiça espacial.
}

A seca, como característica do clima semiárido compôs, durante muito tempo, o principal elemento do imaginário regional das dificuldades individuais e coletivas da população residente devido aos obstáculos impostos à produção agrícola, bem como à própria sobrevivência humana. O fator natural era capaz de explicar a fome e subnutrição de homens, mulheres e crianças, como podemos perceber na clássica obra Geografia da Fome, de Josué de Castro (1984, p. 166-167), 
completo a economia primária da região, extinguindo as fontes naturais de vida, crestando as pastagens, dizimando o gado e arrasando as lavouras, reduzem o sertão a uma paisagem desértica, com seus habitantes sempre desprovidos de reservas, morrendo à míngua de água e de alimentos. Morrendo de fome aguda ou escapando esfomeados, aos magotes, para outras zonas, fugindo atemorizados à morte que os dizimaria de vez na terra devastada.

[...] São as chuvas incertas, com um regime pluviométrico de uma irregularidade espetacular, que tornam o clima nordestino um fator de degradação da vida do homem nesta região. Desta irregularidade das chuvas resultam desde o empobrecimento progressivo do solo pela erosão até as crises calamitosas de fome na região.

Os territórios da seca construíram no imaginário coletivo uma territorialidade simbólica, cultural e material passiva dos azares climáticos, isto é, a "utilização de aspectos particulares da natureza na construção de um imaginário coletivo de uma sociedade e a instrumentalização desse imaginário para ações de base política no seu território" (CASTRO, 1997, p. 181).

As políticas de combate à seca durante a fase hidráulica que foi representada pela criação de órgãos nacionais como a Inspetoria de Obras Contra as Secas (IOCS, Decreto $n^{\circ} 7.619$, de 21 de outubro de 1909) atual Departamento de Obras Contra as Secas (DNOCS), perdurou até 1945, quando a questão das implicações geográficas do semiárido ganha uma ótica mais plural, não atribuindo todos os seus flagelos ao reducionismo das adversidades climáticas. Segundo Pomponet (2009, p. 60)

Até então, a promiscuidade política produzira muitas obras com recursos públicos em propriedades particulares, o sistema social se estruturara de forma que a população sertaneja era mantida sob as amarras dos poderosos locais e a questão fundiária, uma das raízes do drama das secas, permanecia um tabu.

Não querendo aqui nos alongarmos sobre o histórico das políticas de combate à seca, tema que já dispõe de vasta literatura, ressaltamos que a adentrada do DNOCS à lógica do Desenvolvimento Regional, proposta a partir da década de 1950, pouco diferiu da era do IOCS na sua fase hidráulica. Além do mais, órgãos como DNOCS e SUDENE não conseguiam abarcar todos os flagelos decorrentes dos períodos de estiagem, tão pouco desviar-se dos vícios da elite agrária local que continuava a corromper as obras desses órgãos. Segundo descreve Pomponet (2009, p. 62),

\footnotetext{
Nova seca se abateu sobre a região em 1969-1970 e a SUDENE e o DNOCS não se mostraram capazes de agir com eficiência diante do flagelo. E, contrariando o discurso oficial, o órgão permaneceu realizando obras em propriedades particulares, principalmente nas de quem tinha assento no Congresso Nacional. A hipocrisia, a pusilanimidade e uma severa estiagem entre 1979 e 1983 produziram nova tragédia no Nordeste, com milhões de mortos e flagelados.
}

Uma nova abordagem para superar os problemas dos Sertões Secos vem acontecer mais tarde, na década de 1990, durante o governo de Fernando Henrique Cardoso, em decorrência das influências externas de modernização do campo e a configuração geográfica do mundo rural que se adotara no Brasil e no mundo. Estas discussões prosseguem no decorrer nos anos 1990 e é permeado por políticas e programas modelados ao contexto da política de mercado (SCHNEIDER, 2009). 
Seguindo a política de modernização do campo do governo anterior, a partir de 2003, com o presidente Luiz Inácio Lula da Silva o Estado brasileiro apresentou uma série de projetos hídricos a serem implantados no país com o propósito de mitigar as problemáticas causadas pelas secas, principalmente no semiárido brasileiro, e minimizar as disparidades entre as grandes regiões brasileiras com o desenvolvimento de uma agricultura irrigada moderna entre outros sistemas de abastecimento e acumulação de água. Nesse sentido para Santos e Silveira (2001, p.52) "o território ganha novos conteúdos e impõe novos comportamentos, graças às enormes possibilidades da produção e, sobretudo, da circulação de insumos, dos produtos, do dinheiro, das ideias, das informações, das ordens e dos homens."

Nesse contexto, algumas ações forma implementadas na última década ou como experimentais ou como programas, entre elas o PIMIC (Programa de formação e mobilização social para convivência com o semiárido: um milhão de cisternas rurais), iniciado em julho de 2003, o programa P1+2 (Programa de formação e mobilização social para a convivência com o semiárido: uma terra e duas águas), com o objetivo de assegurar terra e água para consumo humano e agropecuário (CARVALHO, 2009). Dentro desse mesmo contexto o Programa de Aceleração do Crescimento (PAC) em parceria com o governo do estado alagoano está executando o Canal do Sertão de Alagoas. É a maior obra do Governo Federal no estado. O Canal, em final de plano, poderá conduzir $32 \mathrm{m3} / \mathrm{s}$ para atender diversas demandas hídricas do sertão alagoano. Pensado na década de 1980, este projeto terá seu maior impulso com a sua inserção em 2007 no PAC, sendo entregue 3 trechos do Canal já concluídos, dois em 2013 e um em de 2015.

\section{A Territorialização do Canal do Sertão}

O semiárido alagoano possui uma extensão territorial de aproximadamente $12,5 \mathrm{mil} \mathrm{km²}$, com 76.118 estabelecimentos, em 902. 614 de área em hectares, distribuídos por 38 municípios, onde predomina o clima quente e seco característico da região, com uma precipitação pluvial média que varia entre 400 e 600 mm, distribuídos irregularmente ao longo do ano (IBGE, 2006) (EMBRAPA, 1997). Além do clima regional, o semiárido é também assinalado pelo predomínio de solos rasos e de baixa fertilidade (Costa et al., 2011), o que limita a produção agrícola na região.

Devido às adversidades climáticas e a dificuldade de uma produção agrícola diversificada, em 1998 a Companhia de Desenvolvimento dos Vales do São Francisco e do Parnaíba - CODEVASF deu início aos estudos de viabilidade do aproveitamento integrado dos recursos hídricos em Alagoas buscando a introdução no espaço semiárido alagoano de um empreendimento que fosse capaz de minimizar os problemas de uma das áreas com os piores indicadores socioeconômicos do país (VIEIRA et al. 2010). Nesse sentido, dentre as intervenções propostas pela CODEVASF está o uso do canal adutor de água do Rio São Francisco, o Canal do 
Sertão, com vistas a contemplar os municípios que sofrem com a escassez de recursos hídricos no Sertão e no Agreste alagoano, sendo eles: Água Branca, Arapiraca, Cacimbinhas, Carneiros, Craíbas, Delmiro Gouveia, Dois Riachos, Estrela de Alagoas, Girau do Ponciano, Igaci, Inhapi, Lagoa da Canoa, Limoeiro de Anadia, Major Isidoro, Minador do Negrão, Monteirópolis, Olho d’Água das Flores, Olho d'Água do Casado, Olivença, Palmeira dos Índios, Pariconha, Piranhas, Santana do Ipanema, São José da Tapera e Senador Rui Palmeira, como demonstra a figura 1.

Figura 1. Mapa do semiárido Alagoano. Fonte: Secretaria do Estado do Planejamento, Gestão e Patrimônio [dados online], (2016) ${ }^{1 .}$

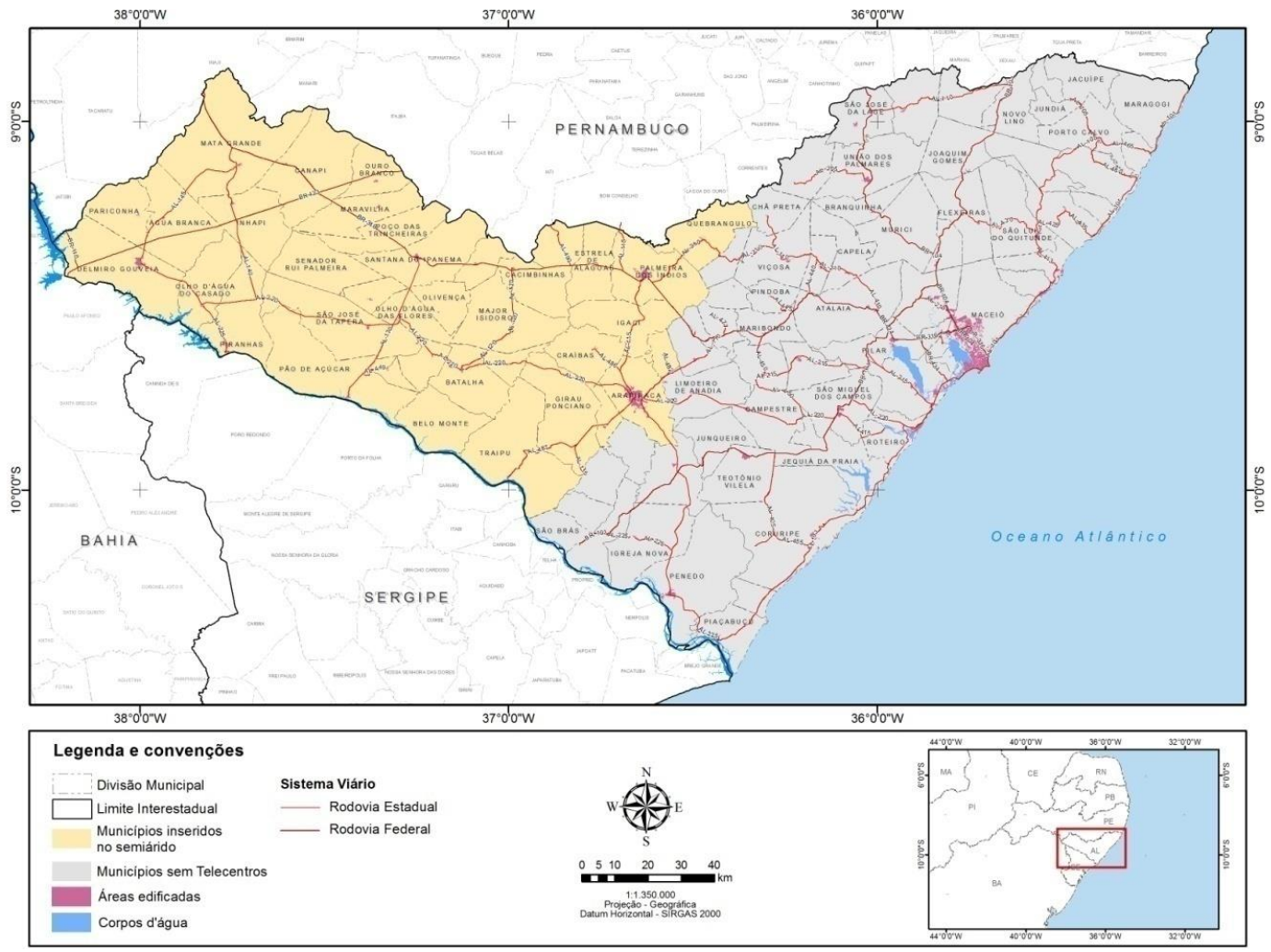

Destacamos que o Canal do Sertão é a maior obra hídrica em execução pelo Governo do Estado de Alagoas em conjunto com o Governo Federal, sendo a segunda maior obra do país, ficando atrás apenas da transposição do rio São Francisco, a maior obra hídrica do Brasil. O referido canal tem como objetivo acrescer a disponibilidade hídrica do Sertão e do Agreste alagoano, que são áreas atingidas pelas constantes secas ou por baixos índices pluviométricos, em consequência de sua localização geográfica, isto é, na região semiárida nordestina. Destacamos que esse projeto prevê a utilização das águas do Canal do Sertão para diversas finalidades por meio de estruturas de derivação por gravidade ou por bombeamento (SEMARH, 2014), como podemos observar melhor na figura 2.

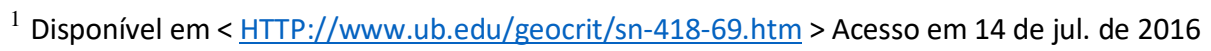


Figura 2. O Canal do Sertão cruzando o município de Delmiro Gouveia. Foto: Wanubya Silva, (2015).

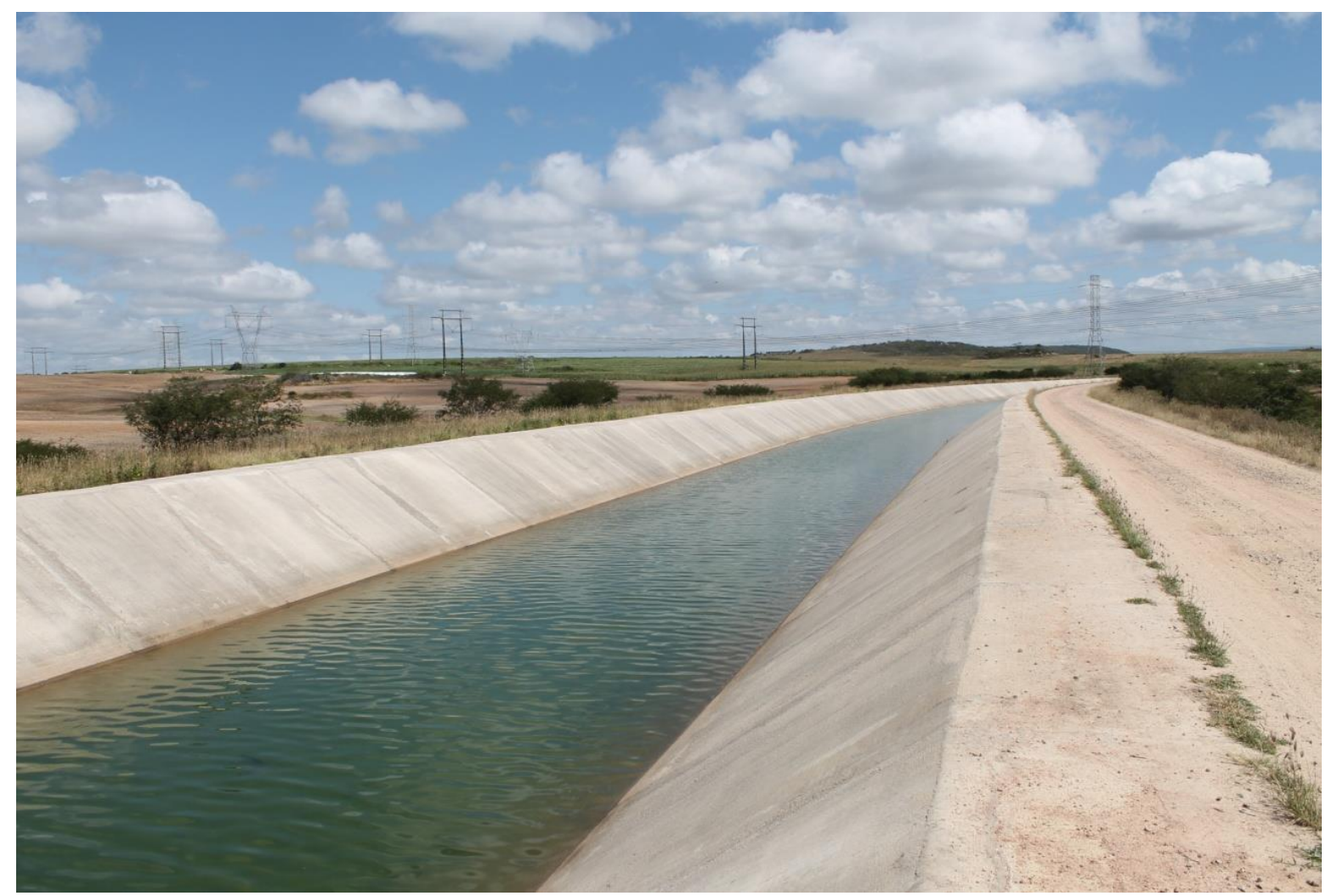

O processo inicial de implantação do canal data da década de 1980, uma vez que a obra foi concebida em 1989, porem o princípio da construção do mesmo ocorreu em 1992, permanecendo estacionada por dez anos por carência de estudos técnicos que comprovassem sua viabilidade. Esta paralisação se prolongou até o ano de 2002, após a execução de um amplo estudo técnico que envolveu ministérios, órgãos federais e estaduais, e a partir de um convênio com a Companhia de Desenvolvimento do Vale do São Francisco e Parnaíba (CODEVASFP) Alagoas pode comprovar a viabilidade do canal. Para isso, foram apontadas as alternativas socioeconômicas de engenharia e os impactos ambientais, levando em conta o aproveitamento da água de parte da bacia hidrográfica do Rio São Francisco, desde o lago do Moxotó, no município de Delmiro Gouveia, próximo à Usina Apolônio Sales, até as imediações de Arapiraca, numa extensão de 250 quilômetros.

Estudos realizados pelo Governo do Estado de Alagoas em conjunto com o IBGE, apontam que o Canal, quando concluído, contemplará parcialmente 06 microrregiões homogêneas do estado, sendo elas: Serrana do Sertão Alagoano, Alagoana do Sertão do São Francisco, Santana do Ipanema, Batalha, Palmeira dos Índios e Arapiraca (SEMARH, 2010). 
Figura 3. Parte do traçado do Canal do Sertão. Fonte: SEMARH, (2014). Elaboração: Antonio Almeida e Wanubya Silva.

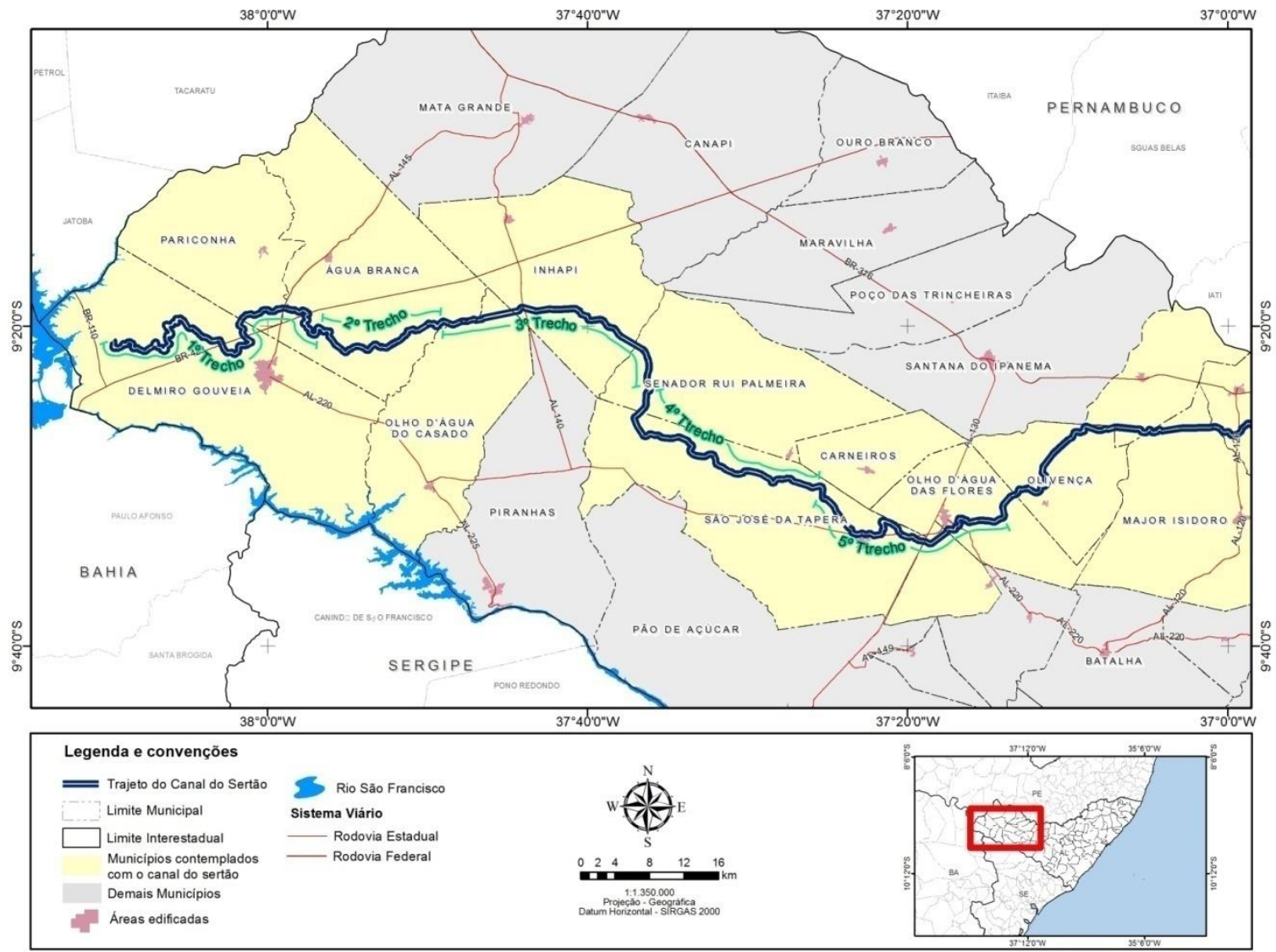

Repercutimos que o objetivo do canal é a garantia do abastecimento de água proveniente da bacia do São Francisco para os municípios do semiárido alagoano, compreendidos no Sertão e no Agreste do estado. 0 projeto prevê além do abastecimento para consumo humano, a viabilização de água para irrigação de projetos de agricultura e pecuária (SEMARH, 2007-2014).

Segundo a Secretaria de Meio Ambiente e Recursos Hídricos do estado de Alagoas (SEMARH), a área que será contemplada pelo canal abrangerá, aproximadamente, $13.230,30 \mathrm{~km}^{2}$, representando $47,36 \%$ da área total do estado, beneficiando diretamente 42 municípios e uma população próxima de um milhão de habitantes. Ainda segundo a secretaria, a utilização da água do canal é prevista para irrigação da agricultura familiar e empresarial, perímetros irrigados, abastecimento humano, dessedentação de animais, psicultura, indústrias e comércio, com abastecimento de pequenos açudes ou os barreiros, como são denominados no Sertão.

Segundo informa o relatório da SEMARH 2007-2014, às margens dos 65 km inaugurados em 2013 se verificou a colheita de hortaliças diferenciadas para a região tais como, rúcula, acelga, alface, além de pimentão, alho poró, tomate cereja e até mesmo morangos. 
O Zoneamento Agroecológico do Estado de Alagoas - ZAAL, realizado pela EMBRAPA, evidencia que a área dos três primeiros trechos já entregues, com $93 \mathrm{~km}$ de extensão, abrangendo os municípios de Delmiro Gouveia, Água Branca, Pariconha, Olho d'Água do Casado, Inhapi e Senador Rui Palmeira, somam uma extensão territorial de $1.287 \mathrm{~km}^{2}$. Segundo o estudo, desse total, os Neossolos quartzarenos $\left(26,17 \mathrm{~km}^{2}\right)$, os Argissolos Vermelho Amarelos $\left(6,31 \mathrm{~km}^{2}\right)$ e os Latossolos Amarelos $\left(2,06 \mathrm{~km}^{2}\right)$, compõem apenas 2,68\% do solo da área. Desses solos, apenas os dois últimos apresentam melhor potencial agrícola; com 3,15\% qualificados como bom potencial para irrigação e para cultivo agrícola (EMBRAPA, 1997).

Mediante as condições físico-naturais que se apresentam no Sertão Seco alagoano é urgente a necessidade de conhecer e discernir sobre as condições reais de cada produtor.

Nesta pesquisa dedicamos nossa atenção as práticas territoriais dos grupos humanos no entorno do Canal do Sertão entre os municípios de Delmiro Gouveia e Água Branca, visto que estes, apesar de se localizarem ambos no alto Sertão alagoano de clima semiárido, apresentam condições físico-naturais como também socioespaciais diferenciadas, sendo Delmiro Gouveia um município em que a maior parte da população vive no perímetro urbano, enquanto Água Branca é um município predominantemente rural.

\section{A Dinâmica Fundiária de Alagoas e a Implantação do Canal do Sertão}

Em Alagoas, com uma economia alicerçada no latifúndio e na produção extensiva a dinâmica fundiária e agrícola pouco se alterou ao longo da sua história. O estado possui uma área de $27,848,2 \mathrm{~km}^{2}$, dividida em três mesorregiões geográficas: Sertão, Agreste e Leste alagoano (figura 4), sua população é de 3.093 .994 habitantes (IBGE, 2010).

Figura 4. Mesorregião do estado de Alagoas. Fonte: Secretaria do Estado do Planejamento, Gestão e Patrimônio [dados online], $2016^{2}$.

\footnotetext{
${ }^{2}$ Disponível em < http://dados.al.gov.br/dataset/mesorregioes-do-estado-de-alagoas Acesso em 21 de jul. de 2016.
} 


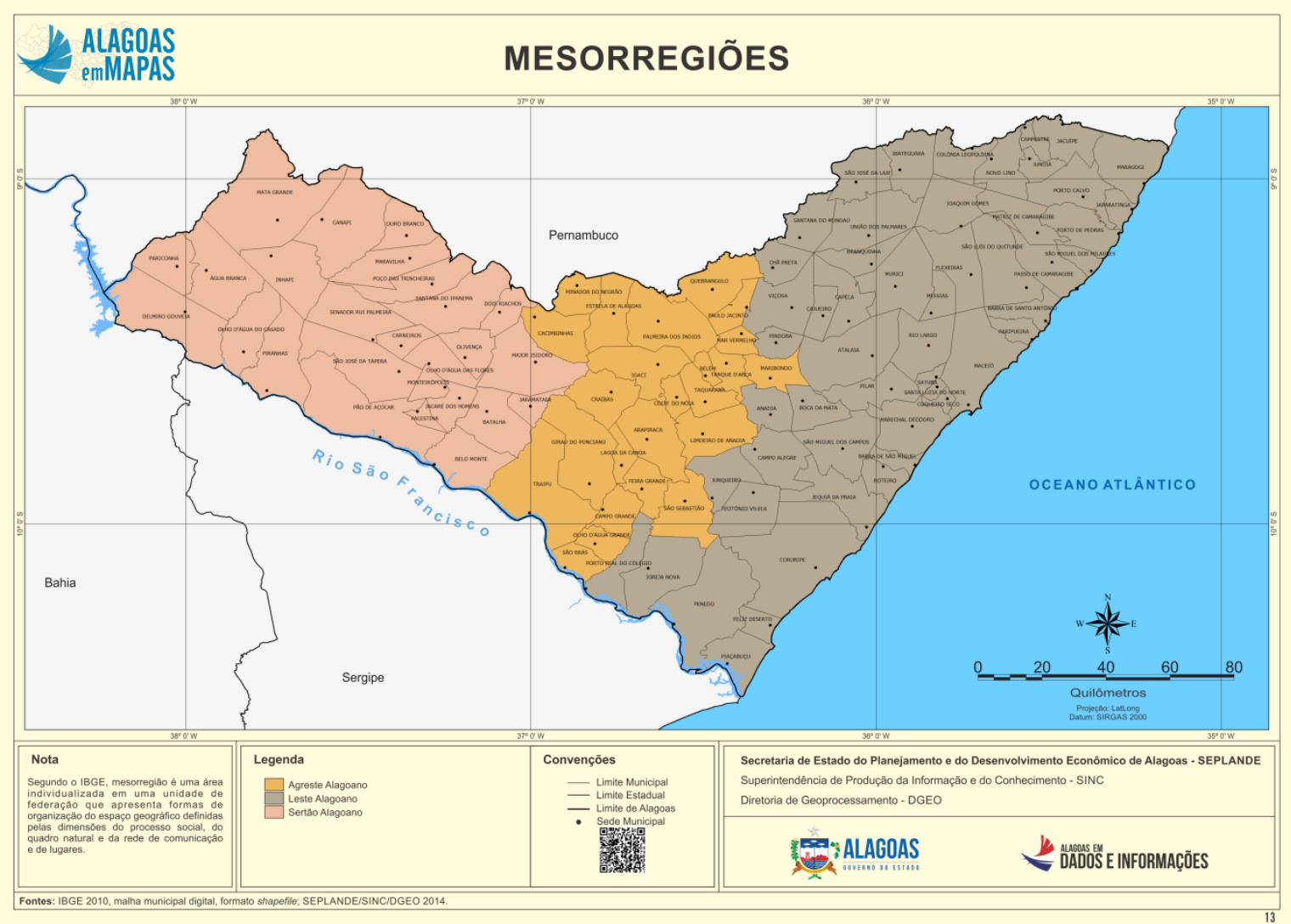

Nesse estado a diversidade climática é pouco complexa, existindo basicamente dois tipos de climas tropical úmido no Litoral Leste e semiárido, que se estende do Sertão ao agreste. Da diversidade climática nasce a dualidade do uso do solo, com extensiva monocultura da cana de açúcar, presente no Litoral Leste faixa da Zona da Mata alagoana, enquanto no interior alagoano destacam-se a pecuária e a policultura.

Enquanto na Zona da Mata seu processo de ocupação e a concentração da terra se alicerçou no uso do solo para o cultivo da cana-de-açúcar, no interior do estado o histórico do seu processo de ocupação e concentração se deu basicamente no uso da terra para a criação de animais ou como reserva de valor. Andrade (2011) relata o trajeto dos Sertões, mostrando como desde o tempo da ocupação do Sertão nordestino, ainda no Brasil colonial, a figura do latifundiário e o uso da terra para a criação do gado, fez parte do histórico da descida para o Sertão.

[...] Até no Cariri cearense pleitearam os homens da Casa da Torre o recebimento das sesmarias. Constituíram, assim, os maiores latifúndios do Brasil, tornando-se senhores de uma extensão territorial maior do que muitos reinos europeus, pois, possuíam, em 1710, em nossos sertões, mais de 304 léguas de terras nas margens do Rio São Francisco e de seus afluentes (ANDRADE, 2011, p.89).

Tudo isso fez do sesmeiro o senhor que, além de dono das grandes extensões de terras virara dono dos vaqueiros, posseiros ou arrendatários que procuravam trabalho. O mesmo tornava-se o político, construtor das leis e inúmeras vezes a própria lei. Assim, foi se configurando o espaço rural sertanejo, dominado por 
latifúndios em oposição aos roçados e aos pequenos produtores de subsistência (ANDRADE, 2011). Estas conjunturas associadas criaram uma política característica no Sertão, em que a posse da terra teve um papel fundamental. Nesse sentido, Castro (2008, p. 302) afirma que,

A estrutura fundiária nordestina que opõe o latifúndio ao minifúndio possui uma dimensão política bastante peculiar, na medida em que a posse da grande propriedade na Região, especialmente no Sertão, está associada a baixos níveis de produção, a utilização da propriedade mais como reserva de valor, não apenas econômica, mas também como simbólico, do que como unidade de produção.

Tradicionalmente a cultura da conservação do solo como reserva de valor está ligada às elites agrárias sertanejas como uma forma de fetiche do ter terra é ter poder, nela se caracterizou e se construíram caricaturas da figura do coronel, do poder político e do apadrinhamento (CASTRO, 2002). Além disso, "as relações precárias de propriedade (assentado sem titulação, arrendatário, parceiro, ocupante e produtor sem área) predominam em mais de 34 mil dessas unidades; ou seja, $28 \%$ do total dos estabelecimentos que, pela pequena dimensão, ocupam apenas 9\% da área agrícola" (CARVALHO, 2012, p. 20). Esse histórico formou a configuração socioespacial da microrregião sertaneja, com poucas alterações ao longo da sua história e uma estrutura fundiária de base latifundiária, com pequenas e médias propriedades familiares no entorno de cidades de porte pequeno e médio, de economia rural girando em torno da produção agrícola e pecuarista.

Para além da desigualdade da posse fundiária as condições naturais do Sertão sempre foram palco para o imaginário tanto cultural quanto determinista. No que concerne a esta afirmação tomamos a reflexão de Ab’Saber (1999), sobre os Sertões nordestinos,

Das velhas e repetitivas noções do ensino médio - herdadas um pouco por todos nós - restaram observações pontuais e desconexas sobre o universo físico e ecológico do Nordeste seco. Sua região interiorana sempre foi apresentada como a terra das chapadas, dotada de solos pobres e extensivamente gretados, habitada por agrupamentos humanos improdutivos, populações seminômades corridas pelas secas, permanentemente maltratadas pelas forças de uma natureza perversa. Muitas dessas afirmações são inverídicas constituindo o enunciado de fatos heterogêneos e desconexos, por processos de aproximações incompletas (AB'SABER, 1999, p. 2).

Esse relato é facilmente observado na obra de Euclides da Cunha "Os Sertões", que responsabiliza às condições naturais os flagelos da população residente desse recorte socioespacial. Um espaço de uso de técnicas arcaicas no processo de produção agrícola, dependente exclusivamente da água da chuva para uma colheita de alimentos de subsistência satisfatória e na criação e dessedentação de animais. Na última década do governo petista, no entanto, o espaço agrário do Sertão alagoano vem recebendo a introdução de novos objetos e ações no meio rural, reconfigurando o seu processo produtivo e o uso do solo.

Novos Objetos e Novas Ações no Espaço Agrário Alagoano: os perímetros irrigados 
Com a dinâmica do mundo globalizado, produto de um meio técnico-científico-informacional que passa a existir a partir da terceira revolução industrial, ocorrida no pós-Segunda Guerra, sobretudo nos anos 1970 e 1980, tem início a quarta fase do capitalismo, o capitalismo informacional. Nessa fase o mundo passa a investir em inovação e a expansão dos modernos sistemas de objetos e sistemas de ações se faz por todo o planeta, embora de forma desigual. Na construção desse contexto, empresas, instituições e diversas tecnologias promoveram um crescente aumento da produtividade e do fluxo de materiais, mercadorias, informações e pessoas. Para Santos (2014, p. 54);

É nesse período, também, que toda a natureza se torna passível de utilização direta ou indireta, ativa ou passiva, econômica ou apenas política. Esse período também se caracteriza pela expansão e predominância do trabalho intelectual e de uma circulação do capital em escala mundial que atribui à circulação (movimento das coisas, valores, ideias) um papel fundamental. Esses dois dados, em conjunto, permitem a aceleração da acumulação, da qual, aliás, são e já agora em escala mundial.

Assim, o capitalismo informacional se universalizou dando condições para a construção de uma globalização que interfere na configuração socioespacial das mais diferentes escalas, isto é, as políticas das sociedades globalizadas não são endógenas aos variados territórios fragmentados e seus "complexos territoriais que constituem a base física do trabalho humano" (SANTOS, 2014, p, 17) mas, o território e a sua configuração é produto de uma rede de locais que estão interconectados e emanam as mensagens dos territórios nacionais dominantes que estarão na supervisão da organização e gerência dos múltiplos territórios.

O maior marco contemporâneo é do desenvolvimento de uma sociedade que se alicerça no meio técnico-científico-informacional. Nesse panorama o sistema capitalista prosperou como nunca antes na história, sistema este regido pelas políticas neoliberais de mercado que alcançam os mais longínquos espaços do globo. No mundo globalizado, as decisões e o controle político e econômico não se cerceiam ao território nacional, mas também são emanados de fora dele, do centro para as periferias do globo de forma hierárquica, são decisões de cima para baixo. As consequências desse processo nas políticas e gestão do território nas palavras de Eduardo (2010, p. 182) é refletida da seguinte forma:

O desenvolvimento imperioso das forças produtivas, intensificado, no transcorrer da história, como tônica da expansão das relações capitalistas e dos conflitos de classes, proporcionou, progressivamente, a desestruturação e o rompimento com a saudosa autogestão do lugar, com os princípios dos desenvolvimentos territoriais autóctones.

O reflexo desse processo é a viabilização de uma geografia mundial intensivamente dinâmica que faz e se refaz mediante às demandas do capital. 
reconstrói uma geografia à sua própria imagem e semelhança. Constrói uma paisagem distintiva, um espaço produzido de transportes e comunicações, de infraestruturas e de organizações territoriais que facilita a acumulação do capital numa dada fase de sua história, apenas para ter de ser desconstruído e reconfigurado a fim de abrir caminho para uma maior acumulação num estágio ulterior (HARVEY, 2012, p. 80-81).

Essa reestruturação ocorre na história das colonizações europeias, durante o mercantilismo e prossegue ao longo da história do mundo se fortalecendo a partir dos anos 1950 com o aparato técnico-científico que chega primeiro nas cidades e se expande para o campo transformando as relações de trabalho no meio rural. Esse evento introduz novos objetos e ações no espaço agrário que se torna, paulatinamente, industrializado. Segundo Santos (2014, p. 92) "a penetração, no campo, das formas mais modernas do capitalismo conduz a dois resultados complementares. De um lado, novos objetos geográficos se criam, fundando uma nova estrutura técnica; de outro a própria estrutura do espaço muda".

É no Brasil pós-Segunda Guerra que os investimentos para que o país adentrasse na lógica globalizadora são realizados de forma mais intensificada. O território brasileiro passa, portanto, por intensas transformações com vistas a adentrar na lógica da globalização, fundamentadas no avanço da ciência, da tecnologia e da informação (LINS, 2008). A gênese da modernização do campo brasileiro ocorre com a participação de insumos e novos objetos inseridos no processo de produção agrícola, "assim, pretendia-se passar de uma agricultura tradicional, totalmente dependente da natureza e praticada por meio de técnicas rudimentares, para uma agricultura mecanizada" (TEIXEIRA, 2005, p. 23).

Essa industrialização do espaço agrário não é, porém, homogênea, combinando, assim, espaços arcaicos com modernos. Essa metamorfose do território nacional brasileiro, portanto, ocorre de maneira desigual entre as regiões do país com forte concentração de um parque industrial no Centro-Sul combinado com regiões tecnologicamente atrasadas, principalmente o Nordeste. Aqui o processo de modernização dos seus meios de produção foi lento, ganhando uma maior dinamização apenas na última década. Segundo Lima (2014, p. 21) "a agricultura brasileira, a partir de meados do século $\mathrm{XX}$, passou por um processo de modernização e industrialização cujas características principais estão presentes na transição dos complexos rurais aos complexos agroindustriais (CAls)."

Dentro do contexto das recentes transformações do campo brasileiro, o Canal do Sertão, apresenta-se como objeto geográfico que busca adentrar a lógica da modernização dos processos de produção no campo do semiárido alagoano. Este pode até mesmo possibilitar uma nova regionalização a partir dos novos usos impostos ao território e construção de uma densidade técnica nos processos produtivos.

O impacto que se projeta, a partir do Canal do Sertão, promete a melhoria e a modernização no processo de produção agrícola para as propriedades familiares, provocando novas territorialidades no uso da terra e da 
produção. Além da implantação de uma fruticultura irrigada por perímetros delimitados pelo Estado, este processo implica em impactos na dinâmica fundiária do entorno do Canal, da pequena à grande propriedade rural. Concernente a isto, pretendemos compreender a partir de um estudo de caso de dois municípios do Alto Sertão alagoano, Delmiro Gouveia e Água Branca, o conteúdo ou intencionalidades contidas no objeto geográfico (Canal do Sertão) pelos sujeitos envolvidos no processo de territorialidades do uso da água do Canal.

\section{As Territorialidades do Uso da Água ao Longo do Canal do Sertão}

As territorialidades dos sujeitos envolvidos no processo de territorialização das águas do Canal do Sertão são múltiplas e se expressam a partir dos múltiplos usos da água, destinadas ao consumo humano, dessedentação de animais, abastecimento domiciliar urbano e rural, além da viabilização de projetos de agricultura e pecuária. Nesses termos, as territorialidades se manifestam nas mais variadas escalas dos fenômenos observados da pequena e média propriedade familiar até aos latifúndios que margeiam o Canal do Sertão nos 95 quilômetros inaugurados.

O Canal do Sertão implica em um concernente e inerente processo de modernização dos meios produtivos, que se materializam no espaço do semiárido alagoano a partir da introdução de novos objetos geográficos e novas ações nos territórios. Dentro desta lógica, destacam-se as metamorfoses que vêm ocorrendo nas atividades agropecuária do espaço agrário brasileiro, de forma que, segundo Matos e Pessoa (2011, p. 292),

\footnotetext{
[...] não seriam possíveis sem a construção de infraestrutura para viabilizar a circulação de pessoas, mercadorias e informações, assim, a modernização da agricultura faz parte do processo de modernização do território. E para o capital, a modernização do território, ou melhor, a adequação dele para obtenção de fluxos deve ser constante. Assim, o modelo modernizante da agricultura depende da e solicita, frequentemente, a modernização do território, visto que a produção é regida por uma economia globalizada, com racionalidade determinada pelo mercado.
}

Assim, ao considerarmos a água matéria desse processo, ela passa a adquirir valor de troca, visto que as possibilidades do uso dos recursos hídricos passam a ser planejados (LINS, 2008). Gerenciada pelo Estado ela é acionada como possibilidade econômica a serviço do capital, ao mesmo tempo tal agente secciona seu uso também às atividades que não estão para atender as suas demandas. Nesse sentido, os usos das águas fazem-se de forma difusa de forma que satisfaz tanto as necessidades mais básicas quanto a hegemonia do sistema patronal de produção.

O estado de Alagoas prevê o uso das águas do Canal em um sistema misto agregando o agronegócio e a agricultura familiar e de subsistência. Para tanto, de forma que se adiantassem estes usos, atendendo à 
demanda, já de muitos séculos, o governo de Alagoas garantiu o uso das águas do Canal do Sertão nos trechos I e II, entregues em 2013, a partir de uma solicitação de outorga à Agência Nacional de Águas em 2010, como informa relatório da SEMARH.

\begin{abstract}
O Governo de Alagoas solicitou a ANA, por meio da Secretaria de Estado da Infraestrutura (SEINFRA) a outorga de direito de uso da água, a qual foi emitida em caráter preventivo, conforme Resolução № 408, de 29 de junho de 2009.

Tendo em vista o respeito às legislações pertinentes, de recursos hídricos e de atos administrativos da ANA, foram expedidos documentos necessários ao bom andamento do processo (Processo no 02501.002018/2001-10), nos quais foram exigidas respostas do Governo de Alagoas, necessárias aos desfechos das avaliações técnicas e posterior emissão do documento de Outorga de Direito de Uso da Água do Canal do Sertão Alagoano (SEMARH, 2010, p. 8).
\end{abstract}

Em resposta à solicitação do estado, a ANA deliberou por conceder Outorga Preventiva do uso dos recursos hídricos do Canal, via Secretaria da Infraestrutura, emitindo Outorga para captação de águas no Reservatório Apolônio Sales/Rio Moxotó, com a finalidade de desenvolver agricultura irrigada, abastecimento rural e urbano e outros usos no trecho Moxotó - Capiá, localizados no município de Delmiro Gouveia, a outorga emitida pela ANA possibilitou também o uso das águas nas etapas subsequentes (SEMARH, 2010).

A outorga deliberada pela ANA autoriza a inauguração dos trechos já concluídos e assim o uso das águas. Nesse sentido, a responsabilidade pelo uso feito pelos produtores rurais passou a ser da SEMARH a partir do decreto número 40.183, de 14 de abril de 2015, publicada no diário oficial do estado, estabelecendo que a SEMARH se responsabiliza pela análise e autorização dos usos da água do Canal do Sertão, através de outorga concedida pelo órgão competente aos produtores que pretendam desenvolver algum tipo de agricultura irrigada a partir das águas do Canal do Sertão. Está outorga é necessária aos produtores rurais que façam uso de mais de 1.000 litros de água por hora, sendo necessária ainda a apresentação de projeto de irrigação junto à secretaria do estado, enquanto os demais produtores terão o uso da água deliberado mediante cadastramento na CODEVASF em conjunto com a SEMARH.

Ainda, no que concerne a outorga de uso da água pelos produtores rurais, segundo o decreto oficial, constata-se que:

Art. 2을 Serão cobrados os usos de recursos hídricos sujeitos a outorga conforme valores a serem definidos pela SEMARH.

Art. 3ㅇ Os usuários da água do Canal Adutor Alagoano com consumo hídrico inferior a 1.000 litros por hora deverão obrigatoriamente requerer cadastramento do seu uso junto a SEMARH em formulário específico, estando isentos de cobrança pelo uso dos recursos hídricos (ALAGOAS, 2015).

O uso antecipado do Canal foi determinado para mitigar os efeitos das estiagens como um plano emergencial para os municípios de Delmiro Gouveia, Pariconha e Água Branca que passaram a fazer uso das águas do Canal, principalmente para o consumo humano e para produção agrícola. Ainda segundo a secretaria, a maior parte dos irrigantes é formada por agricultores de subsistência, destinados às culturas hortícolas, 
frutíferas anuais, feijões de corda, feijão guandu, capim para corte, milho, mandioca e sorgo. Essas culturas em sua maioria são cultivadas em propriedades com uma área de até um hectare, através de irrigação por gravidade (SEMARH, 2014). No entanto, decorrente da intensa concentração fundiária que existe na região, boa parte do Canal do Sertão passa por dentro das terras dos grandes latifundiários locais, que vêm fazendo uso do Canal com aparatos técnicos mais avançados desenvolvendo uma moderna monocultura irrigada. Além disso, a projeção é de paulatinamente ser cada vez mais intensivo o uso da água para fins de irrigação.

Até o presente momento a área que abrange os trechos inaugurados correspondentes a Delmiro Gouveia e Água Branca tem demonstrado que os pequenos e médios produtores rurais destes municípios vêm fazendo uso da água, mesmo que ainda de forma artesanal, em um sistema misto com a produção extensiva em dois latifúndios locais. Este projeto tem impactado na configuração socioespacial do entorno do canal, criando novas territorialidades da pequena à grande propriedade rural em que se instalou o uso das águas do Canal do Sertão.

Partindo da técnica de uso da água, adotada pelos pequenos e médios produtores rurais, que está também intrinsecamente ligada ao processo produtivo, observou-se que nas pequenas e médias propriedades rurais o uso da água vem sendo realizado de forma improvisada por pequenos proprietários rurais que conseguiram custear o equipamento necessário para desenvolver alguns tipos de culturas irrigadas a partir da captação da água por gravidade.

Figura 5. Retirada da água por captação no Povoado Tinguí, Água Branca. Fonte: Wanubya Silva, 2016.

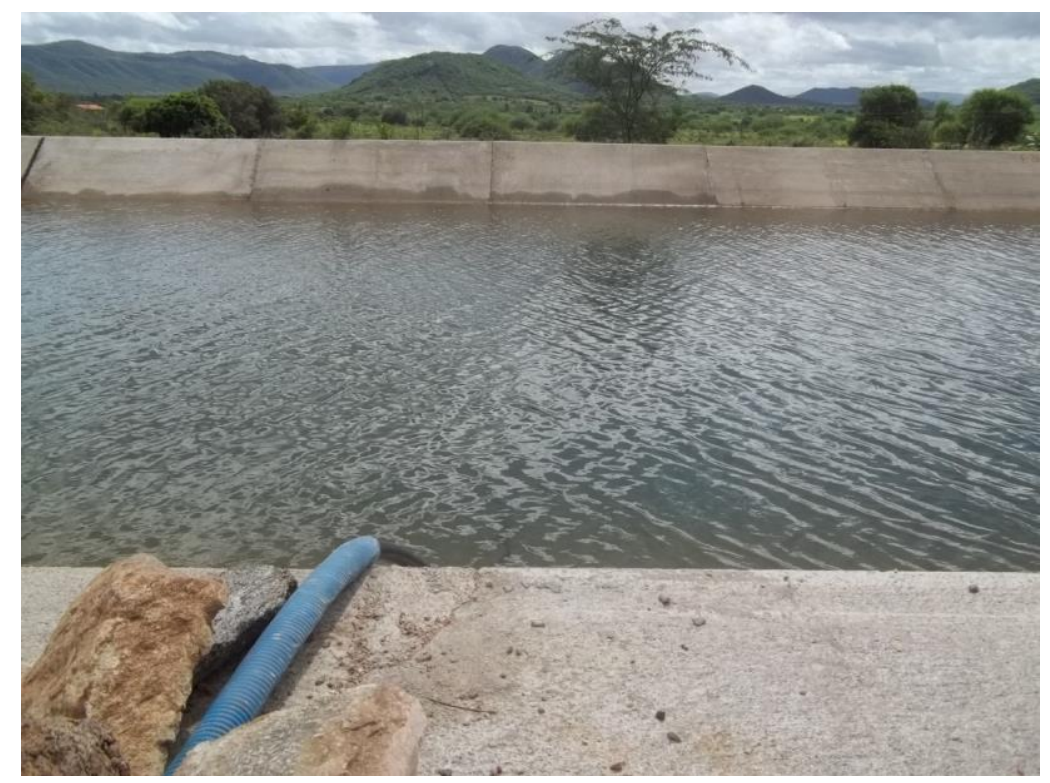


Nesse sentido, o pontuar é que nessas territorialidades encontramos uma agricultura mais diversificada em pequenos estabelecimentos rurais, voltados a atender as demandas internas da própria comunidade, produzindo a maior parte dos alimentos consumidos no dia-a-dia das famílias locais, mesmo sem o aparato técnico do estado, que não tem até o presente momento comparecido com auxílio técnico para o preparo e manejo do solo. Assim, falta orientação técnica para as culturas de irrigação e quais culturas devem ser plantadas.

Contrariamente ao que foi possível observar nas pequenas e médias propriedades que margeiam o Canal, os latifúndios locais se destacam por dispor de aparatos técnicos modernos com orientação agrônoma particulares, isto aliado a uma forte concentração fundiária existente nos municípios, com ênfase para Delmiro Gouveia, município com um único latifúndio detendo mais de 2.000 hectares de terras, enquanto 479 estabelecimentos dividem-se em áreas que variam de 10 a 500 hectares. Em Água Branca também foi identificado um único grande proprietário rural, que vem fazendo uso das águas do Canal. Nesse sentido, tanto no latifúndio em Delmiro quanto em Água Branca o sistema produtivo é voltado para a monocultura irrigada extensiva, como podemos observar na figura 6.

Figura 6. Fonte: SEMARH, (2014). Elaboração: Antonio Almeida e Wanubya Silva.

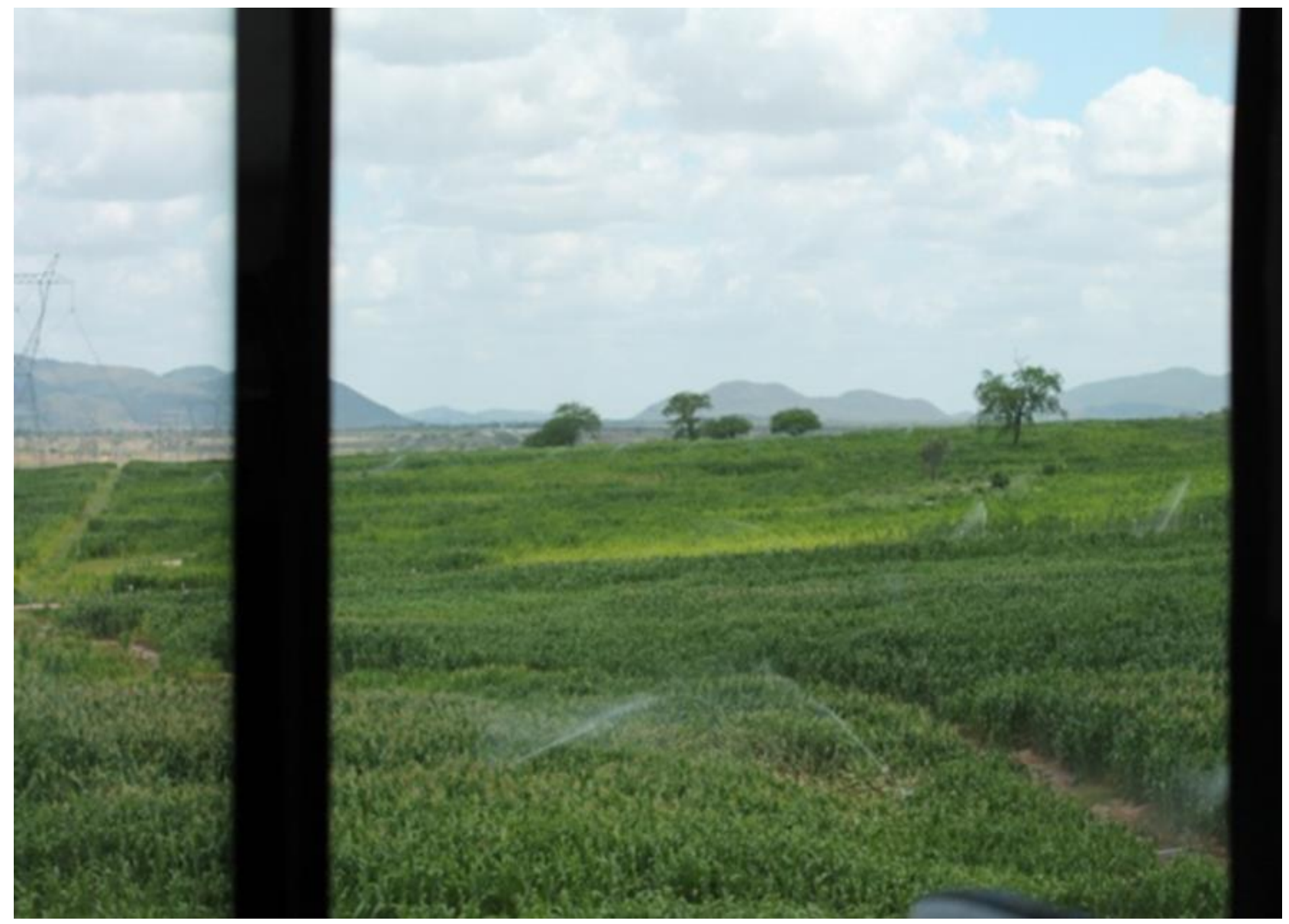


Estes vêm fazendo uso de grandes extensões de terras e arquitetando uma conjuntura agrária que se assemelha àquela adotada no litoral alagoano de forte concentração de fundiária e agroexportadora, modelo que se deu a partir da agricultura de plantation em toda a Zona da Mata alagoana. Aliado a isso, o espaço fundiário alagoano apresenta uma herança de ocupação do território herdado do sistema de sesmarias baseado numa forte concentração de terras destinadas à produção extensiva em dualidade com o roçado. Assim, se configura no recorte socioespacial investigado, uma geografia fundiária em que convive em um extremo, o latifúndio, com reconhecimento legal e naturalizado socialmente, formado por uma elite oligárquica dominante, e em outro extremo, o "roçado", pequenas propriedades, com a formação de uma classe subalterna, com insuficiente proteção legal e aparato técnico do estado, que formou uma massa de pequenos proprietários, posseiros e arrendatários (ANDRADE, 1988).

\section{CONSIDERAÇÕES FINAIS}

Desde a inauguração dos trechos já concluídos o uso das águas do Canal do Sertão vem se intensificando gradativamente desde 2013, com os primeiros 65 km já concluídos e inaugurados. Segundo a SEMARH (2014, p.43) "a paisagem do Sertão tem mudado com a recente presença de um gigantesco rio que se estende por $95 \mathrm{~km}$ concluídos. Ainda segundo a Secretaria do Meio Ambiente e Recursos Hídricos do Estado de Alagoas, a maior parte dos irrigantes é formada por agricultores de subsistência, destinados às culturas hortícolas, frutíferas anuais, feijões de corda, feijão guandu, capim para corte, milho, mandioca e sorgo. Essas culturas em sua maioria são cultivadas em propriedades com uma área de até um hectare, através de irrigação por gravidade (SEMARH, 2014). No entanto, decorrente da intensa concentração fundiária que existe na região, boa parte do Canal do Sertão passa por dentro das terras dos grandes latifundiários locais, que vêm fazendo uso do Canal com aparatos técnicos mais avançados desenvolvendo uma moderna monocultura irrigada. Além disso, a projeção é de paulatinamente ser cada vez mais intensivo o uso da água para fins de irrigação.

Até o presente momento a área que abrange os trechos inaugurados correspondentes a Delmiro Gouveia e Água Branca (Pariconha não participou dos estudos iniciais deste estudo, pois compreendemos que Delmiro Gouveia e Água Branca conseguiram construir uma amostragem inicial dos diversos modos de uso e produção a partir do Canal) vêm demonstrado que os pequenos e médios produtores rurais destes municípios vêm fazendo uso da água, mesmo que ainda de forma artesanal, em um sistema misto com a produção extensiva em dois latifúndios locais. Este projeto tem impactado na configuração socioespacial do entorno do canal, criando novas territorialidades da pequena à grande propriedade rural em que se instalou o uso das águas do Canal do Sertão. 
No Alto Sertão Alagoano, especificamente nos municípios de Delmiro Gouveia e Água Branca, as territorialidades que formam ao longo do Canal do Sertão têm sido múltiplas, se manifestando desde a dinâmica agrícola até ao processo de produção. Os sujeitos beneficiados pelo Canal têm imposto novas ações ao território, refletidas a partir da territorialização das águas do Canal.

Atestamos que embora tenha ocorrido a inserção desse importante objeto geográfico no espaço semiárido alagoano, é concernente que o Estado conheça a realidade de cada produtor, especialmente aqueles que margeiam o Canal e, no entanto, não detêm capital para custear os aparatos técnicos necessários para desenvolverem culturas irrigadas ou para o próprio consumo doméstico. Nesse sentido, cabe ao Estado propor técnicas de cultivo que levem em consideração a capacidade técnica dos sujeitos participantes desse processo, as características fisiográficas do espaço semiárido e o uso eficiente da água, buscando, assim, uma produção tecnicamente apropriada e socialmente justa.

Dentro desse contexto, o Canal do Sertão se apresenta como um rico instrumento técnico para o desenvolvimento coletivo desde o Sertão até o Agreste alagoano, no entanto, é preciso que a ação do Estado se volte para os excluídos da dinâmica globalizadora e não aos interesses dos grupos hegemônicos historicamente privilegiados no processo de formação de Alagoas. Constata-se que isso não vem ocorrendo, pois, em vistas das intencionalidades referidas nos documentos dos órgãos estaduais, o que se ressalta é que o Canal do Sertão formalizará um território possivelmente voltado para o agronegócio e que o desenvolvimento enunciado pelo estado alagoano é, portanto, aquele que preza pelas ideologias neoliberais, com olhar especial para a empresa privada e para o agronegócio.

Contrariamente a este processo, as territorialidades dos pequenos produtores são afirmações da constituição de territórios contra-hegemônicos, em que os usos do território não estão a serviço da demanda do capital, como defende Haesbaert (2014). Além disso, não é difícil conceber a partir de uma análise das intencionalidades referidas nos documentos dos órgãos estaduais que é preciso estar atento para a defesa desses territórios e destas territorialidades, pois como nos alerta Andrade (1998, p. 220),

Convém lembrar que o território construído pela empresa se superpõe ao território construído pelo estado ou pelos estados, apresentando conflitos e complementações. O Estado, sobretudo o autodenominado Estado liberal, está a serviço das empresas e, consequentemente, do jogo de interesses e capacidade de cooptação das mesmas que disputam territórios e mercados, daí a necessidade de se encarar o território e, a territorialidade, como categoria temporária de vez que no espaço e no tempo nada é permanente, tudo se acha em constante transformação.

Nesse sentido, podemos indicar que essa lógica apresentada se assemelha ao pensamento de Peet (2007, p. 24) de que "as políticas de desenvolvimento feitas e importadas pelas instituições do Estado (e agora governança) são ideologias produzidas no interesse das elites político-econômico dominantes" e se fazem presentes nas práticas para o desenvolvimento. Nesses termos, o ideário de desenvolvimento preferido pela 
ordem social dominante, é o desenvolvimento de mercado, pois pretende um desenvolvimento sem romper com as estruturas que criam as barreiras para uma real equidade social.

Nas sociedades da globalização perversa, são nos novos materiais que autorizam novas intencionalidades aplicadas às formas fixas no espaço que o grande capital estrutura e reestrutura os usos dos territórios. Porém, são justamente essas mesmas bases técnicas a serviço do grande capital que poderão "servir a outros objetivos, se forem postas ao serviço de outros fundamentos sociais e políticos" (SANTOS, 2011, p. 10).

Concordamos, portanto, com o professor Milton Santos de que nunca na história das civilizações a humanidade teve antes condições materiais tão grandes de desenvolver uma economia solidária (SANTOS, 2011). Dentro dessa perspectiva, o Canal do Sertão se apresenta, portanto, como uma via de possibilidades para práticas inovadoras dentro do espaço agrário do semiárido alagoano.

\section{REFERÊNCIAS}

AB'SABER, A. N. Sertões e Sertanejos: uma geografia humana sofrida. Estudos Avançados, V. 13, São Paulo, maio-agosto, 1999.

ALAGOAS. Secretaria de Infraestrutura do Estado de Alagoas. Seinfra anuncia conclusão de 65 km do Canal do Sertão. 2013. Disponível em: http://www.infraestrutura.al.gov.br/sala-de-imprensa/noticias/2013/01/seinfra-anuncia-conclusao-de-65-km-docanal-do-sertao. Acesso em: 20 de Set. de 2015.

ANDRADE, M. C. de. A terra e o homem no Nordeste: Contribuição ao Estudo da Questão Agrária no Nordeste. 8. ed. São Paulo: Cortez, 2011.

ANDRADE, M. C. O Nordeste e a questão regional. São Paulo: Ática, 1988.

ANDRADE, M. C. Território, desterritorialidade e novas territorialidades: os limites do poder nacional de do poder local. In: SANTOS, M. SILVEIRA, M. L. Território: globalização e fragmentação. São Paulo: Hucitec, 1998.

CARVALHO, C. P. de. Formação histórica de Alagoas. Maceió: Edufal, 2015.

CARVALHO, C. P. Economia Popular: uma via de modernização para Alagoas. Maceió: Edufal, 2012.

CASTRO, I. E. Da seca como tragédia à seca como recurso: velhos e novos discursos, velhos e novos territórios. Anuário do Instituto de Geociências, São Paulo v. 7, n. 02, p. 1-13, 1996. Disponível em: <http://ppegeo.igc.usp.br/pdf/anigeo/v17/v17a02.pdf >, acesso em 20 de outubro de 2015.

CASTRO, I. E. O problema da escala. In: CASTRO, I. E. de; GOMES, P. C. da C.; CORRÊA, R. L. (Orgs.). Geografia: conceitos e temas. Rio de Janeiro: Bertrand Brasil. 2001.

CASTRO, I, E. Seca versus seca. Novos interesses, novos territórios, novos discursos no Nordeste. In: Paulo César da Costa Gomes, Roberto Lobato Corrêa, (org). Brasil: questões atuais da reorganização do Território. 2. ed. Rio de Janeiro: Bertrand, Brasil, 2002.

CASTRO, I. E. de. Imaginário político e território: natureza, regionalismo, e representação. In: In: CASTRO, I. E. de; GOMES, P. C. da C.; CORRÊA, R. L. (Orgs.). Explorações geográficas: percursos no fim do século. Rio de Janeiro: Bertrand Brasil, 1997.

CASTRO, I. E de. Seca versus seca. Novos interesses, novos territórios, novos discursos no Nordeste. In: CASTRO, I. E. de; GOMES, P. C. da C; CORRÊA, R. L.(Orgs.) Brasil: questões atuais da reorganização do território. Rio de Janeiro: Bertrand Brasil, 2008.

EDUARDO, M. F. As interfaces do desenvolvimento agrário: dependência e conflitualidade. In: SAQUE, M. A. SANTOS, R. A. dos (org.). Geografia Agrária, território e desenvolvimento. São Paulo: Expressão popular, 2010, 256 p.

EMBRAPA. Centro Nacional de Pesquisa de Solos. Manual de métodos de análise de solo. Rio de Janeiro: Embrapa Solos, 1997. 
FARIAS, H. T. M de. Contra as secas: a engenharia e as origens de um planejamento territorial (1877-1938). 2008. Dissertação (Mestrado em Arquitetura e Urbanismo), Universidade Federal do Rio Grande do Norte, Natal, 2008.

HAESBAERT, R. Viver no limite: território e multi/transterritorialidade em tempos de in-segurança e contenção. Rio de Janeiro: Bertrand Brasil, 2014, 320 p.

HAESBAERT, R.O mito da desterritorialização: do fim dos territórios à multiterritorialidade. 3 ed. Rio de Janeiro: Bertrand Brasil, 2007, $400 \mathrm{p}$.

AESBAERT, R; PORTO-GONÇALVES, C. W. A nova des-ordem mundial. São Paulo: UNESP, 2006.

HARVEY, D. Espaços de esperança. São Paulo: Loyola, 2012.

IBGE. Censo Agropecuário 2006. Disponível em< http://www.ibge.gov.br/home/estatistica/economia/agropecuaria/censoagro/2006 > Acesso em 22 de Mai. de 2016.

LICIO, E. C. As trajetórias dos programas de renda mínima e bolsa escola no Brasil: o impacto da variável federativa. 2002. Dissertação (Mestrado em Transformação do Estado e Políticas Públicas) - Fundação Getúlio Vargas Escola de Administração de Empresas de São Paulo, São Paulo, 2002.

LINS, C. L. dos. Os impactos territoriais e socioeconômicos do Canal da (Dês) Integração no Ceará no contexto do Médio e Baixo Jaguaribe. Dissertação (Mestrado em Geografia) -Universidade Estadual do Ceará, Centro de Tecnologia, Fortaleza, 2008

LIMA, I. F. Ocupação espacial do estado de Alagoas. Maceió: Sergasa, 1992.

LIMA, A. A. de. Evolução da agroindústria canavieira alagoana no século XX. Maceió: EDUFAL, 2014.

MATOS, P. F. PESSÔA, V. L. S. A modernidade da agricultura no Brasil e os novos usos do território. Geo UERJ, Ano 13, no. 22, v. 2, 2은 semestre de 2011 p. 290-322.

MORISSAWA, M. A história da luta pela terra e o MST. São Paulo: Expressão Popular, 2001.

PASSADOR et. al. Política públicas de combate a seca no Brasil e a utilização das cisternas na condição de vida das famílias na região do Baixo Salitre (Juazeira-BA): uma dádiva de Deus?. In: Encontro da ANPAD, 31, 2007, Rio de Janeiro, p. 1 - 16.

PEET, Richard. Conceitos e políticas de desenvolvimento: teorias e ideologias. In: FERNANDES, B. M.; MARQUES, M. I. M.; SUZUKI, J. C. (org.). Geografia Agrária: teoria e poder. São Paulo: Expressão Popular, 200

SANTOS, M. SILVEIRA, M. L. Brasil: território e sociedade no início do século XXI. Rio de Janeiro: Record, 2005.

SANTOS, M. Espaço e método. São Paulo. Editora da Universidade de São Paulo, 2014. (Coleção Milton Santos, n. 12)

SANTOS, M. O retorno do território. In: SANTO, M. SILVEIRA, M. L. Território: globalização e fragmentação. São Paulo: Hucitec, 1998.

SANTOS, S. Por uma outra globalização: do pensamento único a consciência universal. 20 ed. Rio de Janeiro: Record, 2011. 